\title{
Effect of Adjuvant Chemotherapy on Stage II Colon Cancer: Analysis of Korean National Data
}

\section{Min Ki Kim, MD ${ }^{1}$ \\ Daeyoun David Won, MD ${ }^{1}$ \\ Sun Min Park, MD' \\ Taejung Kim, MD \\ Sung Ryong Kim, MD' \\ Seong Taek $\mathrm{Oh}, \mathrm{MD}, \mathrm{PhD}^{2}$ \\ Seung Kook Sohn, MD ${ }^{3}$ \\ Mi Yeon Kang, BSN ${ }^{3}$ \\ In Kyu Lee, MD, $\mathrm{PhD}^{1}$}

${ }^{1}$ Department of Surgery, Seoul St. Mary's Hospital, College of Medicine,

The Catholic University of Korea, Seoul,

${ }^{2}$ Department of Surgery, Uijeongbu

St. Mary's Hospital, College of Medicine,

The Catholic University of Korea, Uijeongbu,

${ }^{3}$ Health Insurance Review \& Assessment

Service, Wonju, Korea

Correspondence: In Kyu Lee, MD, PhD

Department of Surgery, Seoul St. Mary's

Hospital, College of Medicine,

The Catholic University of Korea, 222,

Banpo-daero, Seocho-gu, Seoul 06591, Korea

Tel: 82-2-2258-6104

Fax: 82-2-595-2822

E-mail: cmcgslee@catholic.ac.kr

Received April 24, 2017

Accepted December 5, 2017

Published Online December 7, 2017

*This article was revised by the "American Journal Experts" company for English sentences on April 2017, and the certificate verification key number is 1152-1B1F-752F-D429-CCC5.

\section{Purpose}

Debates exist regarding the effectiveness of adjuvant chemotherapy for stage II colon cancer. This study aimed to investigate the current status of adjuvant chemotherapy and its impact on survival for Korean stage II colon cancer patients by analyzing the National Quality Assessment data.

\section{Materials and Methods}

A total of 7,880 patients who underwent curative resection for stage II colon adenocarcinoma between January 2011 and December 2014 in Korea were selected randomly as evaluation subjects for the quality assessment. The factors that influenced overall survival were identified. The high-risk group was defined as having at least one of the following: perforation/ obstruction, lymph node harvest less than 12, lymphovascular/perineural invasion, positive resection margin, poor differentiation, or pathologic $\mathrm{T} 4$ stage.

\section{Results}

The median follow-up period was 38 months (range, 1 to 63 months). Chemotherapy was a favorable prognostic factor for either the high- (hazard ratio [HR], 0.76; 95\% confidence interval [Cl], 0.38 to 0.59; $\mathrm{p}<0.001$ ) or low-risk group (HR, 0.74; 95\% $\mathrm{Cl}, 0.61$ to 0.89; $p=0.002)$ in multivariate analysis. This was also the case in patients over 70 years of age. The hazard ratio was significantly increased as the number of involved risk factors was increased in patients who didn't receive chemotherapy. Adding oxaliplatin showed no difference in survival ( $\mathrm{HR}, 1.36 ; 95 \% \mathrm{Cl}, 0.91$ to 2.03; $\mathrm{p}=0.132)$.

\section{Conclusion}

Adjuvant chemotherapy can be recommended for stage II colon cancer patients, but the addition of oxaliplatin to the regimen must be selective.

\section{Key words}

Adjuvant chemotherapy, Colonic neoplasms, Treatment outcome 


\section{Introduction}

The benefit of adjuvant chemotherapy (AC) for stage III colon cancer is well-established. However, it is debatable for stage II [1-4]. Conclusive randomized controlled trials are lacking, and retrospective small cohort studies have reported conflicting results. The estimated number of needed patients is approximately 5,000 to 8,000 to reliably detect a treatment benefit for AC in stage II colon cancer, with $90 \%$ of power and $18 \%$ relative risk reduction as shown in the NSABP C-01 to C-04 trials [5]. Therefore, it is difficult to obtain the answer to this question through a successful randomized controlled trial.

Despite the limitations of its retrospective design, a study dealing with a nation-wide large scale cohort might answer this question. Recent studies [6-9] that have analyzed data including approximately 2,000 to 150,000 patients with stage II colon cancer have been part of that effort. These studies allow the general patient trends to be identified and minimize the limitations of the retrospective study.

In Korea, the Health Insurance Review and Assessment Service (HIRA), a national government agency, has been evaluating the appropriateness of care for colorectal cancer since 2011, and this initiated large scale data collection about patient baseline characteristics and colorectal cancer management. Our study aimed to investigate the current status and efficacy of AC for stage II colon cancer patients in Korea by analyzing these data.

\section{Materials and Methods}

\section{Data source: National Quality Assessment program in Korea}

In the Korean public health system, the HIRA assesses the appropriateness of the cost of medical services provided by medical institutions and determines the costs to be paid by the National Health Insurance Service. Based on the data that can be obtained through the review process, the HIRA started to evaluate the appropriateness of the treatment of medical institutions for the major diseases, so-called the "National Quality Assessment", and the target diseases have been expanded. The National Quality Assessment program aims to improve the quality of care by giving feedback to medical institutions.

Quality assessment for colorectal cancer treatment has been conducted since 2011. Patients who were diagnosed with colorectal cancer and were charged for the surgical treatment were selected for the evaluation. For the institutions that had more than 150 cases, 150 cases among all cases were randomly selected using computer randomization for each institutional cases. If the institution had less than 150 cases for the examining year, all patients were selected, and their data were sent to the HIRA (however, the reference value was 100 cases for the year 2011 for administrational reasons, not medical or statistical reasons). The National Quality Assessment data are formulated based on the colorectal cancer questionnaire with 21 criteria presented by the HIRA, and information about patient baseline characteristics (admission date, diagnosis, operation name, discharge date, weight, height, etc.), surgery (past surgical history, emergency, the American Society of Anesthesiologists [ASA] grade, completeness of surgery, etc.), pathologic report, and chemotherapy (timing, regimen, usage, etc.) are required to be submitted for the questionnaire.

The total treatment quality grade is determined by a formula calculated for each item in the questionnaire, and the medical institutions are divided into five groups according to this grade. Each year, this rating is officially announced to the general public, so medical institutions are encouraged to actively participate in the National Quality Assessment program. Details of the assessment and its results are available on the internet, but only as Korean version (http://www. hira.or.kr $\rightarrow$ hospital/ pharmacy $\rightarrow$ hospital evaluation information $\rightarrow$ evaluation items: surgery, detailed field: colorectal cancer $\rightarrow$ assessment report).

\section{Patient selection and chemotherapy}

The purpose of this study was to analyze the patients who underwent curative treatment for stage II colon cancer. Therefore, the following patients were excluded from a total 8,639 patients who underwent surgery for colon cancer in 2011-2014 and submitted for the National Quality Assessment: patients without $\mathrm{R} 0$ resection or no data, patients who had received chemotherapy prior to surgery, patients who didn't have the data about any of the risk factor checked specifically in that evaluating year (however, patients were not excluded when there is no data about the status of specific risk factor which was not officially checked for the National Quality Assessment in that evaluating year, patients whose survival could not be confirmed, and those who died within 1 month postoperatively). As a result, a total 7,880 patients were included in the final analysis. The decision to perform chemotherapy was based on the clinical judgment of the medical staff, but it was recommended that 5-fluorouracil (FU) based therapy (with or without oxaliplatin) be started within 8 weeks after surgery when using chemotherapy. 
Table 1. Variables checked for defining high-risk patients at each measuring year

\begin{tabular}{|c|c|c|c|}
\hline & 2011 & 2012 & 2013-2014 \\
\hline Harvested lymph nodes $<12$ & + & + & + \\
\hline Obstruction/Perforation & + & + & + \\
\hline Lymphovascular/Perineural invasion & + & - & - \\
\hline Positive resection margin & - & + & + \\
\hline Poorly differentiation & + & + & - \\
\hline Pathologic T4 & - & - & + \\
\hline
\end{tabular}

“+” means having data, while “-" means having no data about the variable.

\section{Measured outcome}

The primary outcome was overall survival (OS). The OS was calculated from the operation date to the date of death or July 15, 2016 on which survival was finally verified. Survival was confirmed by the termination of health insurance. Patient age, sex, body mass index (BMI), university hospital treatment or not, hospital scale, the ASA grade and emergency surgery or not were presented as baseline data. Known risk factors for survival such as obstruction/perforation, positive resection margin, lymphovascular or perineural invasion, lymph node (LN) harvest less than 12, and pathologic T4 grade were checked selectively according to each year. The patients who had at least one of these factors were placed in the high risk group and those who did not in the low risk group (Table 1).

\section{Statistical analysis}

The clinical characteristics of patients were expressed as number $(\%)$ for categorical variables. Differences between categorical variables were analyzed using the chi-square test or Fisher exact test. The prognostic significance of demographic and pathologic characteristics were determined using univariable and multivariable Cox proportional hazard regression analyses. For cox proportional hazard regression analysis, supremum test for proportionals hazards assumption was performed for checking assumption and it was judged to satisfy the assumption by presenting $p \geq 0.05$. Two-sided $p$-values of $<0.05$ were considered statistically significant.

All statistical analyses were performed using the software package SAS Enterprise Guide ver. 6.1 (SAS Institute, Inc., Cary, NC), R software ver. 3.0.2 (R Foundation for Statistical Computing, Vienna, Austria; http://www.r-project.org) with the support and supervision of the Clinical Research Coordinating Center of the Catholic University of Korea which consisted of statistical experts.

\section{Results}

\section{Patient characteristics}

Of the total 7,880 patients, $4,645(59.0 \%)$ were males, and $3,414(43.3 \%)$ were over 70 years of age. ASA classification I-II was $6,461(82.0 \%)$, and emergency surgeries were performed in $616(7.8 \%)$. There were 2,196 patients $(27.9 \%)$ in the high risk group, and 5,684 (72.1\%) in the low risk group. Among the high risk group, 1,900 (86.5\%) had one risk factor, $280(12.8 \%)$ had two, and $16(0.7 \%)$ had more than three.

In the high risk group, 1,333 (60.7\%) received $\mathrm{AC}$, whereas 2,758 (48.5\%) of the low-risk patients received AC. Males, 70 years of age or younger, BMI over 18, and the ASA classification I-II were more likely to receive AC in the entire cohort. More $\mathrm{AC}$ was performed for the low risk group patients in the general hospitals than in tertiary hospitals. In the high risk group, the patients who underwent emergent surgery or had more than one risk factor were less likely to receive AC. The proportion of patients who received $\mathrm{AC}$ was higher when there was lymphovascular or perineural invasion, or pathologic T4 grade, but the differentiation had no effect on whether patients received AC. Patients who had negative resection margin or LN harvest more than 12 received $\mathrm{AC}$ more (Table 2).

\section{Effect of AC on survival in the whole patients}

The median follow-up period was 38 months (range, 1 to 63 months). Death was occurred in 866 patients (11.0\%) during the study period. The OS was higher in patients with AC (hazard ratio [HR], $0.48 ; 95 \%$ confidence interval [CI], 0.42 to 0.55 ; $<0.001$ ), female, younger, BMI over 18 , tertiary hospital, and ASA grade I-II in univariate analysis. In terms of risk factors, emergency surgery caused by obstruction or perforation, lymphovascular or perineural invasion, harvested LNs less than 12, and pathologic T4 grade had an adverse effect on survival, but positive margin or differentiation did 


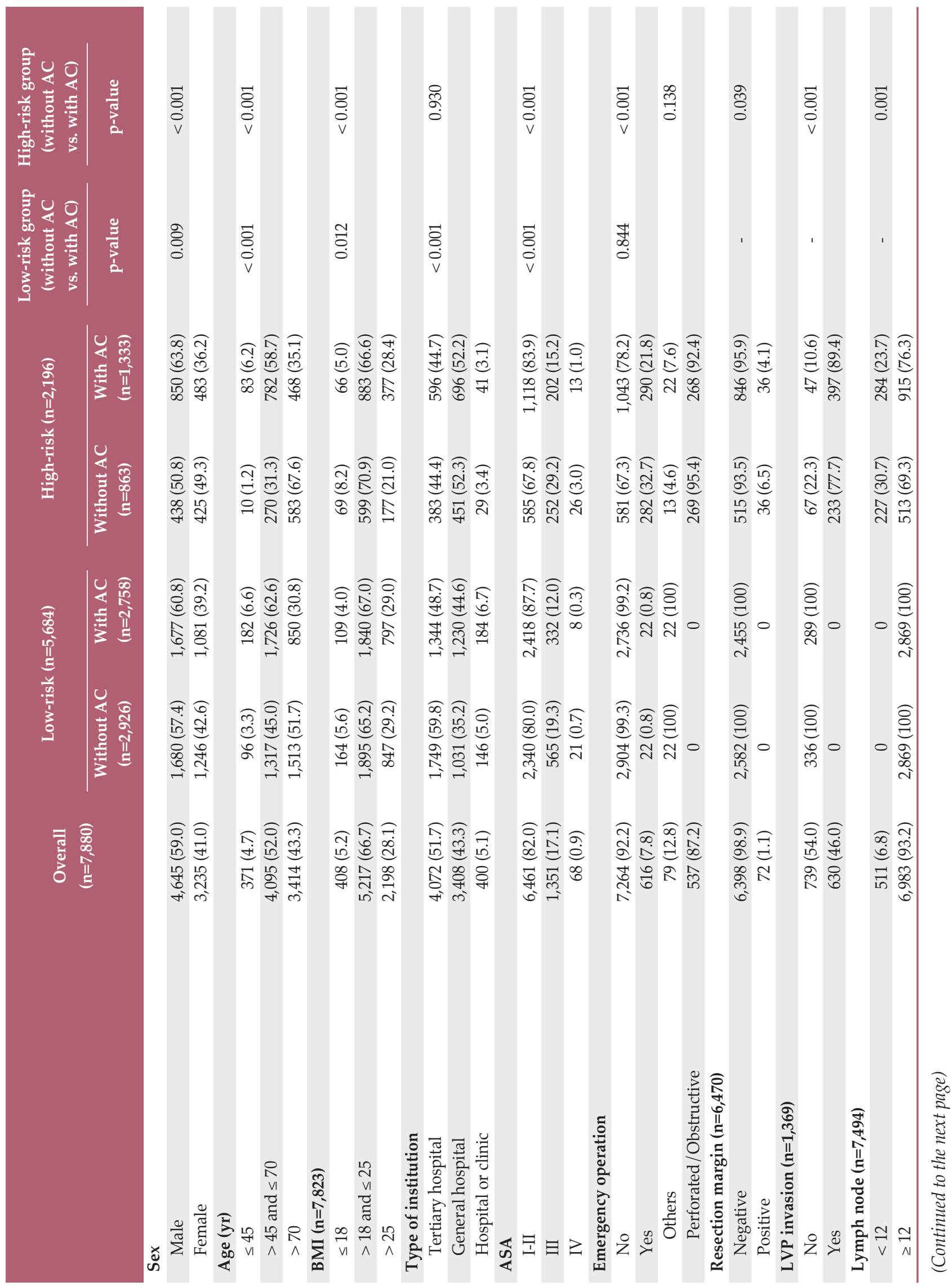




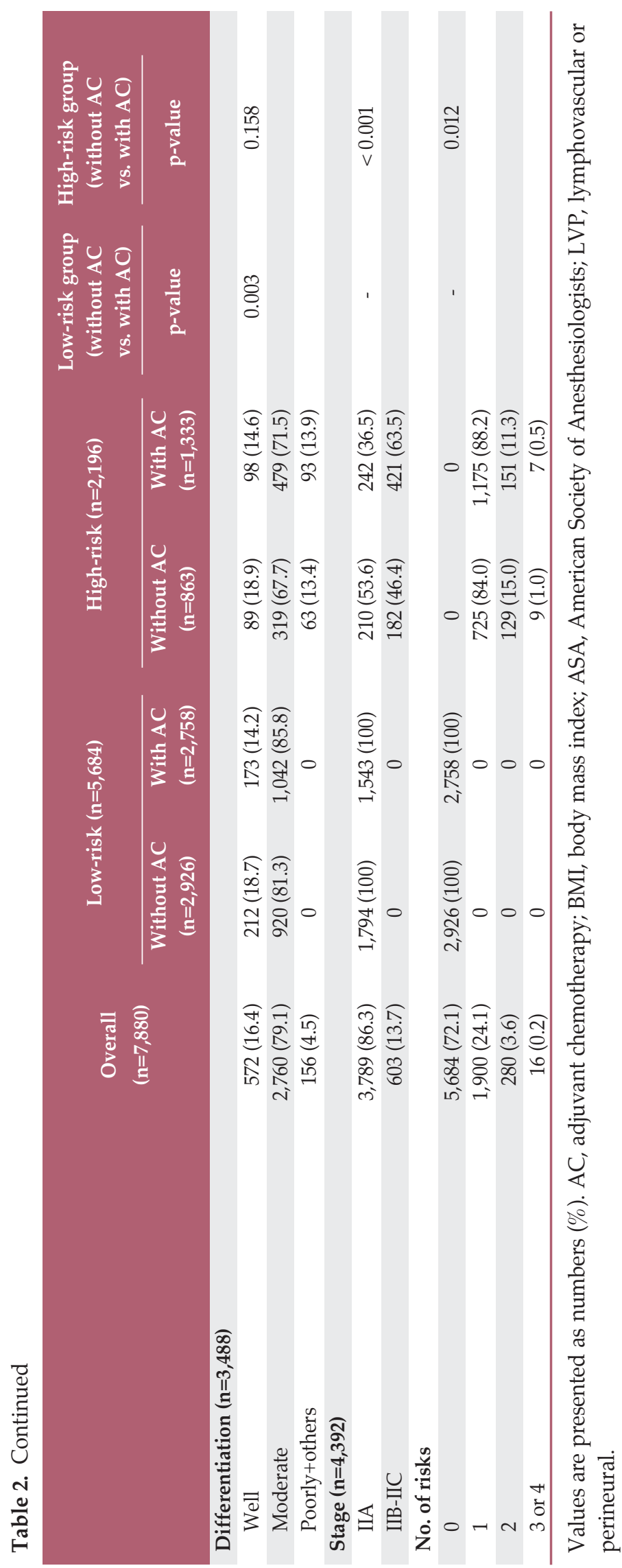


Table 3. Univariate and multivariate analysis of risk factors for survival in whole patients

\begin{tabular}{|c|c|c|c|c|c|c|}
\hline & \multirow{2}{*}{$\begin{array}{c}\text { Alive } \\
(n=7,014)\end{array}$} & \multirow{2}{*}{$\begin{array}{c}\text { Death } \\
(n=866)\end{array}$} & \multicolumn{2}{|c|}{ Univariate analysis } & \multicolumn{2}{|c|}{ Multivariate analysis } \\
\hline & & & HR $(95 \%$ CI $)$ & p-value & HR $(95 \%$ CI $)$ & p-value \\
\hline \multicolumn{7}{|l|}{ Adjuvant chemotherapy } \\
\hline Without AC & $3,234(85.4)$ & $555(14.6)$ & Reference & & & \\
\hline With AC & $3,780(92.4)$ & $311(7.6)$ & $0.48(0.42-0.55)$ & $<0.001$ & & \\
\hline \multicolumn{7}{|l|}{ No. of risks } \\
\hline 0 & $5,198(91.4)$ & $486(8.6)$ & Reference & & & \\
\hline 1 & $1,600(84.2)$ & $300(15.8)$ & $1.75(1.52-2.02)$ & $<0.001$ & & \\
\hline 2 & $206(73.6)$ & $74(26.4)$ & $3.08(2.41-3.93)$ & $<0.001$ & & \\
\hline 3 or 4 & $10(62.5)$ & $6(37.5)$ & $4.44(1.99-9.94)$ & $<0.001$ & & \\
\hline Low-risk $(<1)$ & $5,198(91.4)$ & $486(8.6)$ & Reference & & & \\
\hline High-risk ( $\geq 1)$ & $1,816(82.7)$ & $380(17.3)$ & $1.93(1.69-2.21)$ & $<0.001$ & & \\
\hline \multicolumn{7}{|l|}{ Combination of risk and $\mathrm{AC}$} \\
\hline Low-risk and without AC & $2,616(89.4)$ & $310(10.6)$ & Reference & & Reference & \\
\hline Low-risk and with $\mathrm{AC}$ & $2,582(93.6)$ & $176(6.4)$ & $0.56(0.47-0.68)$ & $<0.001$ & $0.73(0.60-0.87)$ & 0.001 \\
\hline High-risk and without AC & $618(71.6)$ & $245(28.4)$ & $2.65(2.24-3.13)$ & $<0.001$ & $1.73(1.43-2.10)$ & $<0.001$ \\
\hline High-risk and with AC & $1,198(89.9)$ & $135(10.1)$ & $0.85(0.69-1.04)$ & 0.106 & $0.84(0.68-1.04)$ & 0.115 \\
\hline \multicolumn{7}{|l|}{ Sex } \\
\hline Male & $4,096(88.2)$ & $549(11.8)$ & Reference & & Reference & \\
\hline Female & $2,918(90.2)$ & $317(9.8)$ & $0.82(0.71-0.94)$ & 0.004 & $0.66(0.57-0.76)$ & $<0.001$ \\
\hline \multicolumn{7}{|l|}{ Age (yr) } \\
\hline$\leq 45$ & $361(97.3)$ & $10(2.7)$ & Reference & & Reference & \\
\hline$>45$ and $\leq 70$ & $3,873(94.6)$ & $222(5.4)$ & $2.05(1.09-3.87)$ & 0.026 & $1.92(1.02-3.63)$ & 0.044 \\
\hline$>70$ & $2,780(81.4)$ & $634(18.6)$ & $7.92(4.24-14.8)$ & $<0.001$ & $5.44(2.90-10.20)$ & $<0.001$ \\
\hline \multicolumn{7}{|l|}{ BMI $(n=7,823)$} \\
\hline$\leq 18$ & $317(77.7)$ & $91(22.3)$ & $2.23(1.79-2.78)$ & $<0.001$ & $1.77(1.41-2.21)$ & $<0.001$ \\
\hline$>18$ and $\leq 25$ & $4,614(88.4)$ & $603(11.6)$ & Reference & & Reference & \\
\hline$>25$ & $2,043(93.0)$ & $155(7.1)$ & $0.59(0.49-0.70)$ & $<0.001$ & $0.73(0.61-0.87)$ & 0.001 \\
\hline \multicolumn{7}{|l|}{ Type of institution } \\
\hline Tertiary hospital & $3,667(90.1)$ & $405(10.0)$ & Reference & & Reference & \\
\hline General hospital & $2,975(87.3)$ & $433(12.7)$ & $1.34(1.17-1.53)$ & $<0.001$ & $1.20(1.04-1.38)$ & 0.011 \\
\hline Hospital or clinic & $372(93.0)$ & $28(7.0)$ & $0.71(0.49-1.05)$ & 0.083 & $1.00(0.68-1.47)$ & 0.985 \\
\hline \multicolumn{7}{|l|}{ ASA } \\
\hline I-II & $5,925(91.7)$ & $536(8.3)$ & Reference & & Reference & \\
\hline III & $1,045(77.4)$ & $306(22.7)$ & $3.14(2.73-3.61)$ & $<0.001$ & $1.94(1.67-2.25)$ & $<0.001$ \\
\hline IV & $44(64.7)$ & $24(35.3)$ & $5.33(3.54-8.03)$ & $<0.001$ & $2.12(1.37-3.30)$ & 0.001 \\
\hline \multicolumn{7}{|l|}{ Emergency operation } \\
\hline No & $6,561(90.3)$ & $703(9.7)$ & Reference & & Reference & \\
\hline Yes & $453(73.5)$ & $163(26.5)$ & $3.13(2.64-3.71)$ & $<0.001$ & $1.71(1.39-2.09)$ & $<0.001$ \\
\hline Others & $63(79.8)$ & $16(20.3)$ & Reference & & & \\
\hline Perforated/Obstructive & $390(72.6)$ & $147(27.4)$ & $1.84(1.09-3.09)$ & 0.022 & & \\
\hline \multicolumn{7}{|l|}{ Resection margin $(n=6,470)$} \\
\hline Negative & $5,744(89.8)$ & $654(10.2)$ & Reference & & & \\
\hline Positive & $63(87.5)$ & $9(12.5)$ & $1.18(0.61-2.27)$ & 0.631 & & \\
\hline \multicolumn{7}{|l|}{ LVP invasion $(n=1,369)$} \\
\hline No & $651(88.1)$ & $88(11.9)$ & Reference & & & \\
\hline Yes & $525(83.3)$ & $105(16.7)$ & $1.44(1.08-1.91)$ & 0.013 & & \\
\hline \multicolumn{7}{|l|}{ Lymph node $(\mathrm{n}=7,494)$} \\
\hline$<12$ & $425(83.2)$ & $86(16.8)$ & Reference & & & \\
\hline$\geq 12$ & $6,281(90.0)$ & $702(10.1)$ & $0.63(0.50-0.79)$ & $<0.001$ & & \\
\hline
\end{tabular}

(Continued to the next page) 
Table 3. Continued

\begin{tabular}{|c|c|c|c|c|c|c|}
\hline & \multirow{2}{*}{$\begin{array}{c}\text { Alive } \\
(n=7,014)\end{array}$} & \multirow{2}{*}{$\begin{array}{c}\text { Death } \\
(n=866)\end{array}$} & \multicolumn{2}{|c|}{ Univariate analysis } & \multicolumn{2}{|c|}{ Multivariate analysis } \\
\hline & & & HR $(95 \% \mathrm{CI})$ & p-value & HR $(95 \% \mathrm{CI})$ & p-value \\
\hline \multicolumn{7}{|c|}{ Differentiation $(n=3,488)$} \\
\hline Well & $491(85.8)$ & $81(14.2)$ & Reference & & & \\
\hline Moderate & $2,403(87.1)$ & $357(12.9)$ & $0.9(0.71-1.15)$ & 0.396 & & \\
\hline Poorly+others & $126(80.8)$ & $30(19.2)$ & $1.38(0.91-2.1)$ & 0.129 & & \\
\hline \multicolumn{7}{|l|}{ Stage $(n=4,392)$} \\
\hline IIA & $3,480(91.8)$ & $309(8.2)$ & Reference & & & \\
\hline IIB-IIC & $514(85.2)$ & $89(14.8)$ & $1.89(1.49-2.39)$ & $<0.001$ & & \\
\hline
\end{tabular}

The HR in multi-variate analysis was adjusted for sex, age, BMI, type of institutions, ASA, and emergency operation. HR, hazard ratio; CI, confidence interval; AC, adjuvant chemotherapy; BMI, body mass index; ASA, American Society of Anesthesiologists; LVP, lymphovascular or perineural.

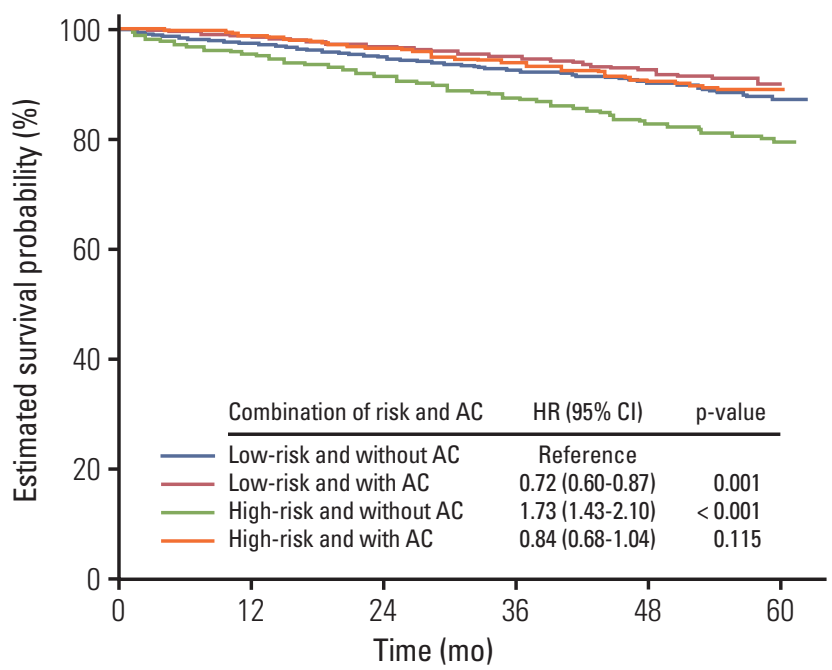

$\begin{array}{lrrrrrr}\text { No. at risk } & & & & & & \\ \text { Low-risk and without AC } & 2,926 & 2,819 & 2,305 & 1,472 & 813 & 99 \\ \text { Low-risk and with AC } & 2,758 & 2,716 & 2,369 & 1,595 & 870 & 94 \\ \text { High-risk and without AC } & 863 & 777 & 364 & 444 & 313 & 76 \\ \text { High-risk and with AC } & 1,333 & 1,311 & 1,136 & 821 & 536 & 142\end{array}$

Fig. 1. Adjusted survival probability curve from multi-variate cox regression analysis of four categories classified according to the risk status and adjuvant chemotherapy (AC) in the whole patients. Survival probability was adjusted for sex, age, body mass index, type of institutions, American Society of Anesthesiologists, and emergency operation. HR, hazard ratio; CI, confidence interval.

not. The more the risk factors involved, the lower the survival rate.

In the multivariate analysis, the effects of individual risk factors and $\mathrm{AC}$ were not analyzed because the presence or absence of risk factors and with or without $\mathrm{AC}$ were divided into four categories and then analyzed. This analysis showed that male gender, age greater than 70, BMI 18 or less and greater than 25, general hospital treatment and ASA grade over II had adverse effects on the OS (Table 3).

When the group of patients who had no risk factors and did not receive AC was used as a reference category, the HR was decreased in cases of receiving AC in patients who had 


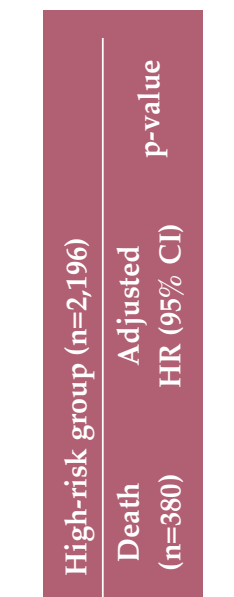

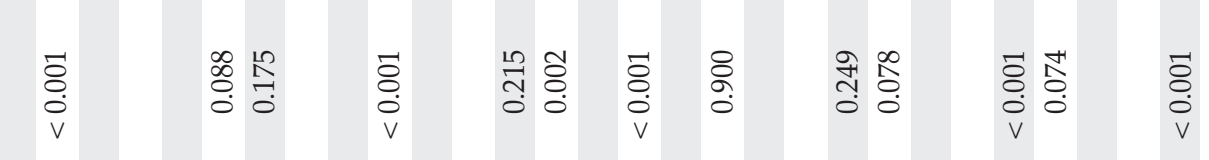

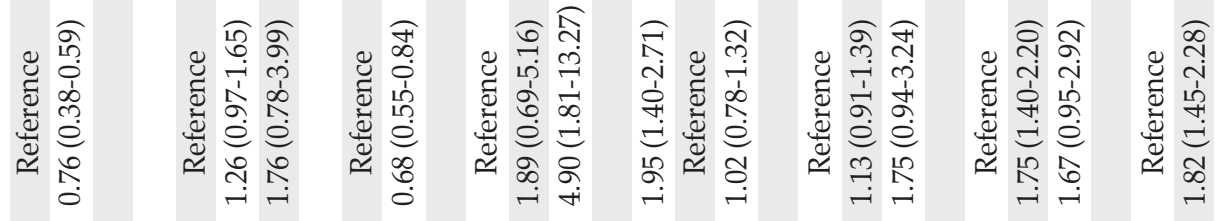

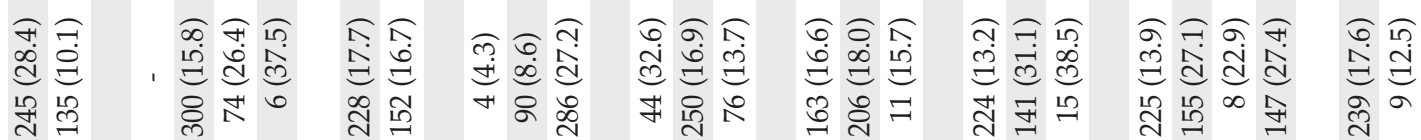

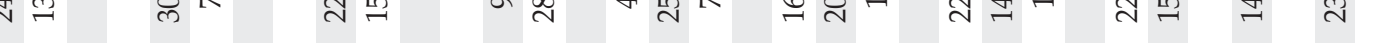

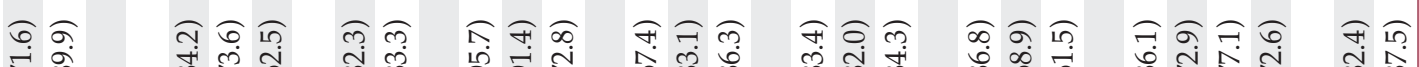

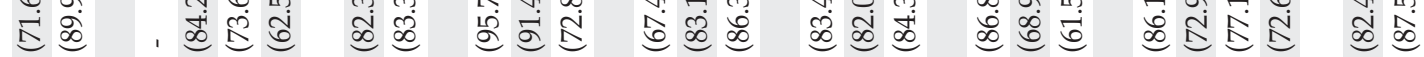
北告

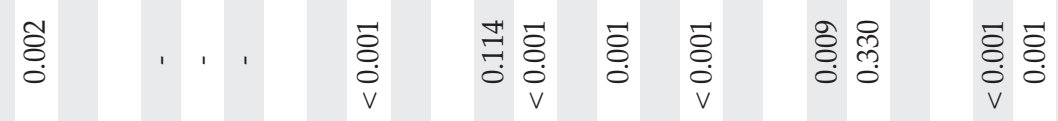

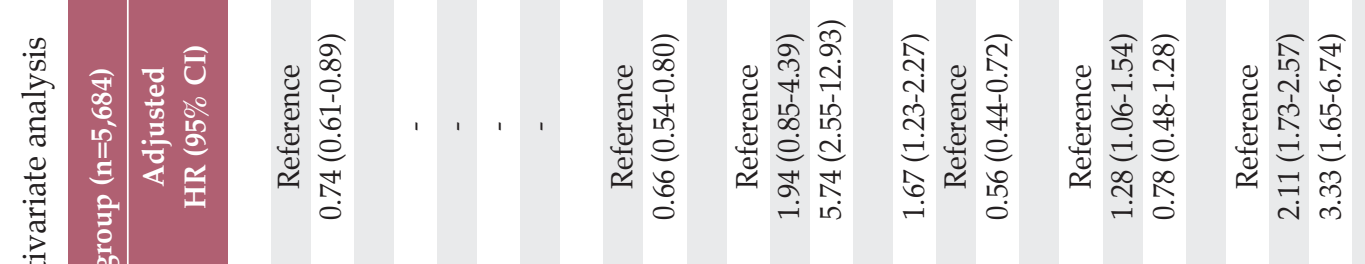

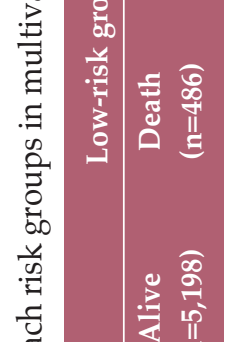

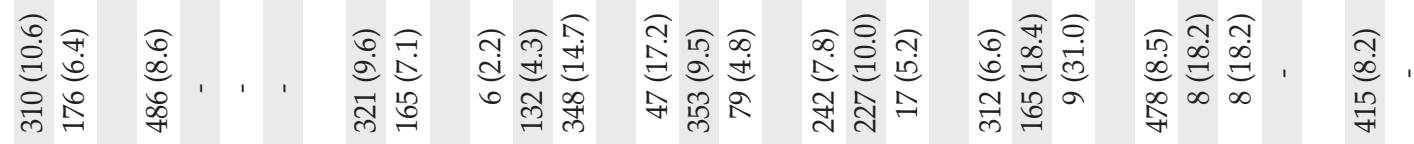

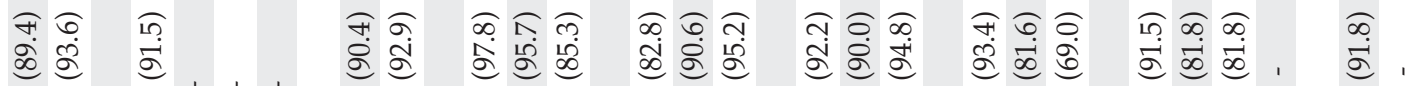

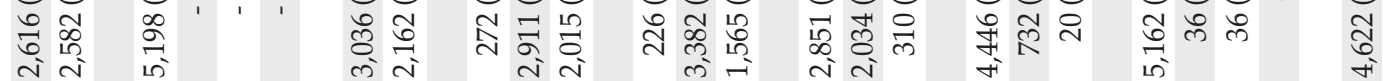

๖ั้
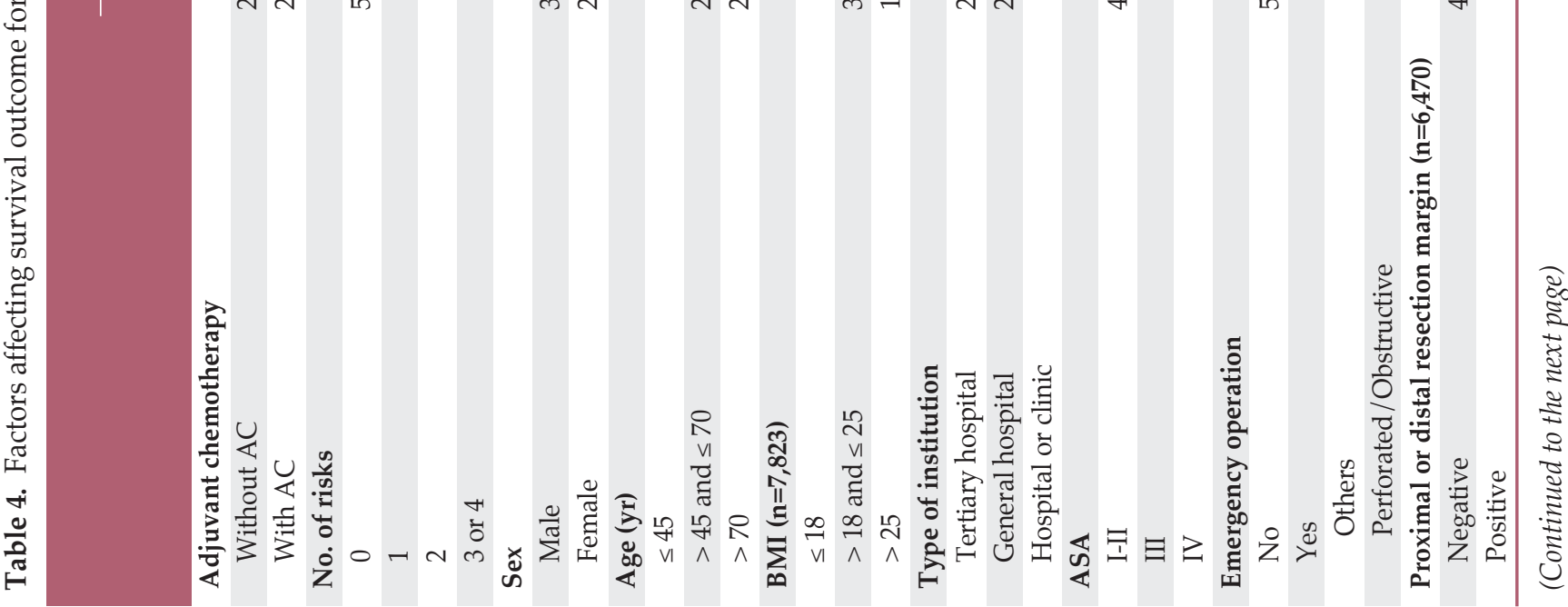


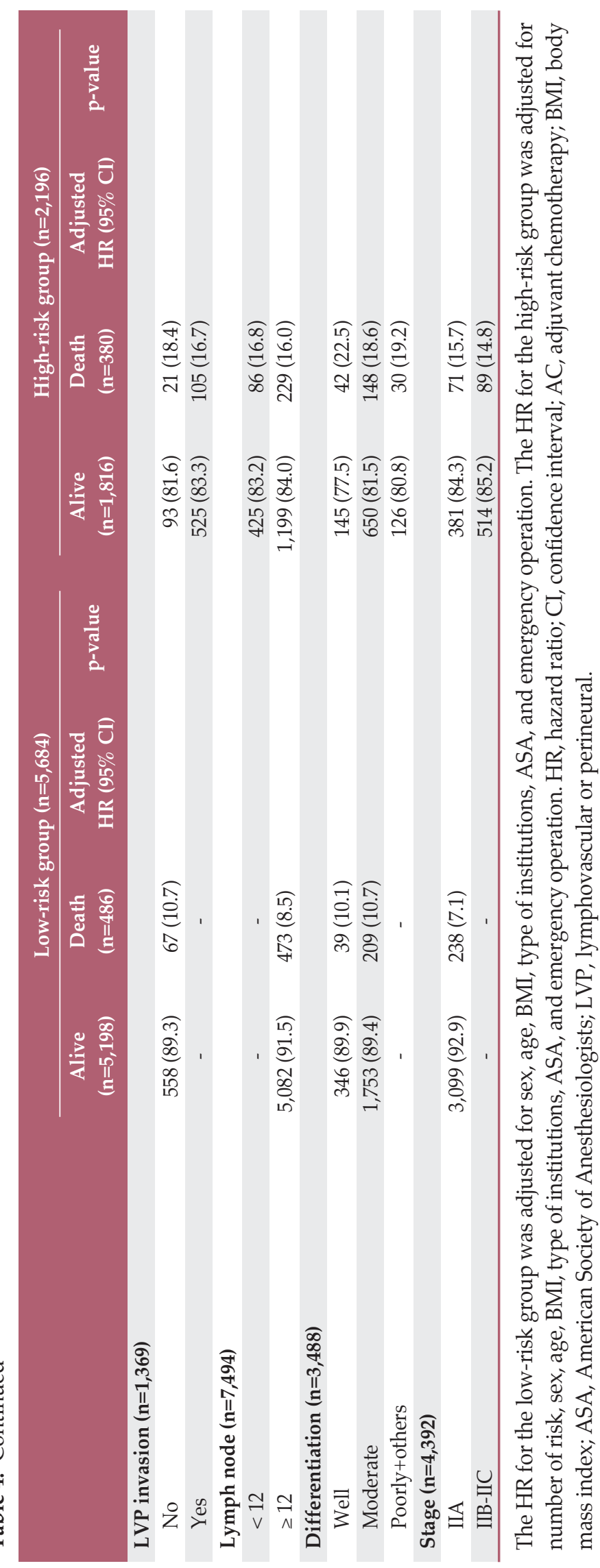



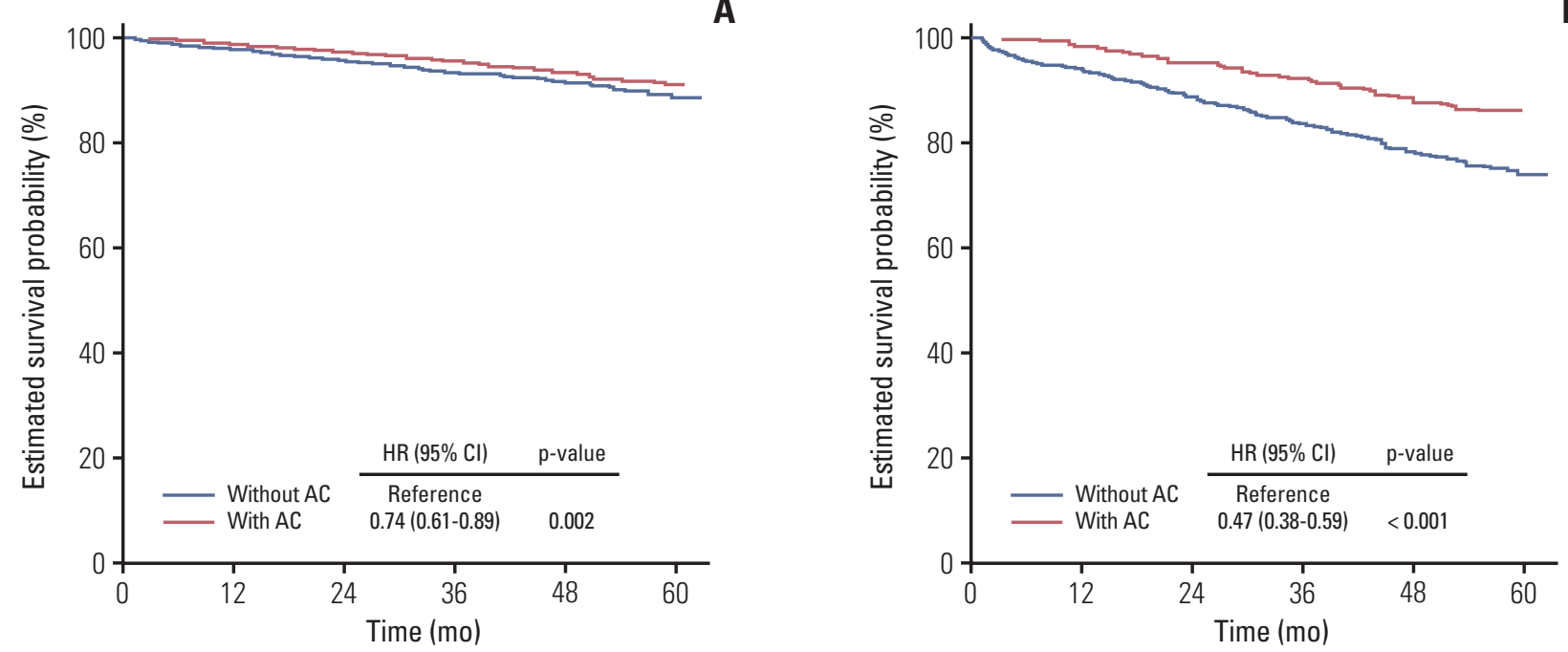

$\begin{array}{lllllll}\text { No. at risk } & & & & & & \\ \text { Without AC } & 2,926 & 2,819 & 2,305 & 1,472 & 813 & 99 \\ \text { With AC } & 2,758 & 2,716 & 2,369 & 1,595 & 870 & 94\end{array}$

$\begin{array}{lrrrrrr}\text { No. at risk } & & & & & & \\ \text { Without AC } & 863 & 777 & 634 & 444 & 313 & 76 \\ \text { With AC } & 1,333 & 1,311 & 1,136 & 821 & 536 & 142\end{array}$

Fig. 2. Adjusted survival curve of stage II colon cancer patients according to the chemotherapy. (A) Low-risk group (adjusted for sex, age, body mass index [BMI], type of institutions, American Society of Anesthesiologists [ASA], and emergency operation). (B) High-risk group (adjusted for number of risk, sex, age, BMI, type of institutions, ASA, and emergency operation). AC, adjuvant chemotherapy; $\mathrm{HR}$, hazard ratio; $\mathrm{CI}$, confidence interval.

no risk factors (adjusted $\mathrm{HR}, 0.73$; $95 \% \mathrm{CI}, 0.60$ to 0.87 ; $\mathrm{p}=0.001$ ). On the contrary, when the patient who had risk factors did not receive AC, the HR was increased (adjusted HR, $1.73 ; 95 \% \mathrm{CI}, 1.43$ to $2.10 ; \mathrm{p}<0.001)$. However, the hazard ratio showed no significant difference compared with the reference group when the high risk group patients received $\mathrm{AC}$ (adjusted HR, 0.84; 95\% CI, 0.68 to 1.04; $\mathrm{p}=0.115$ ) (Fig. 1).

\section{Effect of AC on survival in the low-risk group}

For the low-risk group, AC, female, aged 70 or younger, BMI 18 or less and greater than 25 , tertiary hospital treatment (compared to general hospital), and ASA grade I-II were favorable factors for survival either in the univariate and multivariate analysis (Table 4, S1 Table). In particular, AC was shown to reduce the relative risk of death by $26 \%$ after adjusting for the effects of other factors (HR, $0.74 ; 95 \% \mathrm{CI}$, 0.61 to $0.89 ; \mathrm{p}=0.002$ ) (Fig. 2A).

\section{Effect of AC on survival in the high-risk group}

Whether the patient received AC, the number of involved risk factors, age, BMI, ASA grade, and emergency surgery were the identified factors that had significant impact on sur- vival in univariate analysis of the high-risk patients (S1 Table). However, individual known risk factors such as obstruction/ perforation, positive resection margin, lymphovascular or perineural invasion, harvested LNs less than 12, poor differentiation, or pathologic T4 stage did not affect survival. The results of multivariate analysis are presented as Table 4 .

The multivariate analysis revealed that without AC (HR of $\mathrm{AC}, 0.76 ; 95 \% \mathrm{CI}, 0.38$ to $0.59 ; \mathrm{p}<0.001)$, male, age greater than 70 , BMI 18 or less and greater than 25, and ASA grade over II worsened the survival outcome (Table 4, Fig. 2B).

\section{Relationship between chemotherapy and number of involved risk factors in high-risk group}

The effect of the number of involved risk factors on survival in patients receiving chemotherapy and those not receiving chemotherapy was examined (Table 5). In the multivariate analysis in which the sex, age, BMI, type of institutions, ASA grade, and emergency operation were adjusted, the hazard ratio was significantly increased as the number of involved risk factors increased in patients who did not receive $\mathrm{AC}$ (when the patients with no involved risk factors was the reference group, an HR of one involved risk factor 
Table 5. Relationship of adjuvant chemotherapy and number of involved risk factors

\begin{tabular}{|c|c|c|c|c|c|c|}
\hline & Alive & Death & $\begin{array}{c}\text { HR } \\
(95 \% \mathrm{CI})\end{array}$ & p-value & $\begin{array}{c}\text { Adjusted } \\
\text { HR }(95 \% \text { CI) }\end{array}$ & p-value \\
\hline \multicolumn{7}{|c|}{ Without chemotherapy $(n=3,789)$} \\
\hline \multicolumn{7}{|c|}{ No. of risks } \\
\hline 0 & $2,616(89.4)$ & $310(10.6)$ & Reference & & Reference & \\
\hline 1 & $530(73.1)$ & $195(26.9)$ & $2.50(2.08-2.99)$ & $<0.001$ & $1.59(1.29-1.96)$ & $<0.001$ \\
\hline$\geq 2$ & $88(63.8)$ & $50(36.2)$ & $3.60(2.67-4.86)$ & $<0.001$ & $1.67(1.19-2.36)$ & 0.003 \\
\hline \multicolumn{7}{|c|}{ With chemotherapy $(n=4,091)$} \\
\hline \multicolumn{7}{|c|}{ No. of risks } \\
\hline 0 & 2,582 (93.6) & $176(6.4)$ & Reference & & Reference & \\
\hline 1 & $1,070(91.1)$ & $105(8.9)$ & $1.32(1.03-1.68)$ & 0.026 & $1.16(0.90-1.50)$ & 0.249 \\
\hline$\geq 2$ & $128(81.0)$ & $30(19.0)$ & $2.88(1.95-4.27)$ & $<0.001$ & $2.53(1.63-3.92)$ & $<0.001$ \\
\hline
\end{tabular}

The HR was adjusted for sex, age, body mass index, type of institutions, American Society of Anesthesiologists, and emergency operation. HR, hazard ratio; $\mathrm{CI}$, confidence interval.

Table 6. Effect of adjuvant chemotherapy on stage II colon cancer patients who are aged over 70

\begin{tabular}{|c|c|c|c|c|c|c|c|}
\hline Risk group & Adjuvant treatment & Alive & Death & $\begin{array}{c}\text { HR } \\
(95 \% \mathrm{CI})\end{array}$ & p-value & $\begin{array}{c}\text { Adjusted } \\
\text { HR }(95 \% \text { CI) }\end{array}$ & p-value \\
\hline \multirow[t]{2}{*}{ Low-risk $(\mathrm{n}=2,535)$} & Without chemotherapy & $1,356(84.4)$ & $250(15.6)$ & Reference & & Reference & \\
\hline & With chemotherapy & $812(87.4)$ & $117(12.6)$ & $0.74(0.60-0.93)$ & 0.008 & $0.75(0.60-0.94)$ & 0.012 \\
\hline \multirow[t]{2}{*}{ High-risk $(\mathrm{n}=1,122)$} & Without chemotherapy & $399(65.7)$ & $208(34.3)$ & Reference & & Reference & \\
\hline & With chemotherapy & $429(83.3)$ & $86(16.7)$ & $0.42(0.33-0.54)$ & $<0.001$ & $0.48(0.37-0.63)$ & $<0.001$ \\
\hline
\end{tabular}

The HR for the low-risk group was adjusted for sex, age, BMI, type of institutions, ASA, and emergency operation. The HR for the high-risk group was adjusted for number of risk, sex, age, BMI, type of institutions, ASA, and emergency operation. HR, hazard ratio; CI, confidence interval; BMI, body mass index; ASA, American Society of Anesthesiologists.

Table 7. Effect of adding oxaliplatin for high-risk patients on survival in multivariate analysis

\begin{tabular}{|c|c|c|c|c|c|c|}
\hline & $\begin{array}{c}\text { Alive } \\
(\mathrm{n}=1,054)\end{array}$ & $\begin{array}{c}\text { Death } \\
(\mathrm{n}=105)\end{array}$ & $\begin{array}{c}\text { HR } \\
(95 \% \mathrm{CI})\end{array}$ & p-value & $\begin{array}{c}\text { Adjusted } \\
\text { HR }(95 \% \text { CI) }\end{array}$ & p-value \\
\hline \multicolumn{7}{|l|}{ Regimen } \\
\hline $\begin{array}{l}\text { 5-FU/ leucovorin or capecitabine or } \\
\text { UFT/ leucovorin or LV5FU2 }\end{array}$ & $536(90.5)$ & $56(9.5)$ & Reference & & Reference & \\
\hline FLOX or FOLFOX or mFOLFOX & $518(91.4)$ & $49(8.6)$ & $0.97(0.66-1.43)$ & 0.882 & $1.36(0.91-2.03)$ & 0.132 \\
\hline \multicolumn{7}{|l|}{ Age (yr) } \\
\hline$\leq 45$ & $72(97.3)$ & $2(2.7)$ & Reference & & Reference & \\
\hline$>45$ and $\leq 70$ & $660(94.0)$ & $42(6.0)$ & $2.27(0.55-9.35)$ & 0.258 & $2.30(0.56-9.51)$ & 0.251 \\
\hline$>70$ & $322(84.1)$ & $61(15.9)$ & $6.58(1.61-26.88)$ & 0.009 & $6.41(1.54-26.66)$ & 0.011 \\
\hline \multicolumn{7}{|l|}{ ASA } \\
\hline I-II & $911(92.5)$ & $74(7.5)$ & Reference & & Reference & \\
\hline III & $136(82.4)$ & $29(17.6)$ & $2.68(1.74-4.12)$ & $<0.001$ & $1.98(1.27-3.08)$ & 0.003 \\
\hline IV & $7(77.8)$ & $2(22.2)$ & $4.25(1.04-17.36)$ & 0.044 & $3.19(0.78-13.08)$ & 0.107 \\
\hline
\end{tabular}

HR, hazard ratio; CI, confidence interval; FU, fluorouracil; UFT, tegafur-uracil; LV, leucovorin; FLOX, fluorouracil, leucovorin, and oxaliplatin; FOLFOX, folinic acid, fluorouracil, and oxaliplatin; mFOLFOX, modified FOLFOX regimen; ASA, American Society of Anesthesiologists. 
was 1.59 [95\% CI, 1.29 to 1.96], $\mathrm{p}<0.001, \mathrm{HR}$ of two or more of involved risk factors was 1.67 [95\% CI, 1.19 to 2.36], $\mathrm{p}=0.003$ ). However, there was no survival difference between no risk factors involved and one risk factor involved in patients who received AC (HR, 1.16; 95\% CI 0.90 to 1.50; $\mathrm{p}=0.249$ ), though more than two involved risk factors significantly worsened survival outcome (HR, 2.53; 95\% CI, 1.63 to $3.92 ; \mathrm{p}<0.001$ ).

\section{AC for patients older than 70 years of age}

There were 2,535 low-risk and 1,122 high-risk patients among the patients aged 70 years or older. After adjustment for sex, age, BMI, type of institutions, ASA grade and emergency surgery (and number of risk in the high-risk group), AC was an independent prognostic factor for survival in both the low-risk (HR, 0.75; 95\% CI, 0.60 to $0.94 ; \mathrm{p}=0.012)$ and the high-risk ( $\mathrm{HR}, 0.48 ; 95 \% \mathrm{CI}, 0.37$ to 0.63 ; $\mathrm{p}<0.001)$ groups (Table 6).

\section{Effect of adding oxaliplatin to chemotherapy regimen}

Comparisons of OS were made according to the different chemotherapy regimens among the high-risk group patients (Table 7). There were a total of 1,333 high-risk patients who received $\mathrm{AC}$ in the study period, and among them, 174 patients were excluded from the analysis because they used more than two of the recommended regimens or their regimen was not covered by the National Health Insurance system during the whole study period. Among the remaining 1,159 high-risk patients, 592 patients received 5-FU-based AC without oxaliplatin (5-FU/leucovorine, capecitabine, tegafur-uracil/leucovorin, LV5FU2), and the other 567 patients received oxaliplatin (FLOX, FOLFOX, mFOLFOX). After adjustment for other factors, there was no significant difference in OS between the two groups (HR, 1.36; 95\% CI, 0.91 to $2.03 ; \mathrm{p}=0.132$ ).

\section{Discussion}

The most important result of this study was that AC was revealed to have favorable effect on survival for Korean stage II colon cancer patients regardless of their high- or low-risk group assignments. This is consistent with the randomized controlled trial of the Quasar Collaborative Group [2], which reported a $16 \%$ reduction in all-cause mortality using LF chemotherapy for stage II colorectal cancer, and the study of Casadaban et al. [6], which reported that AC was a favorable prognostic factor in both the high-risk and low-risk groups based on 153,000 American stage II colon cancer patients.

However, there are still many contradictory results from other recently published papers. A study analyzing a large dataset of 2,488 Canadian patients reported that AC had no effect on survival either for the high-risk patients or the whole patient cohort [7]. Verhoeff et al. [9] and Kumar et al. [10] analyzed 10,935 and 1,697 patients, respectively, and concluded that only pathologic T4 stage among the risk factors necessitated AC. In particular, the later showed that AC in the low-risk group could decrease the relapsing free survival. Lewis et al. [11] announced that AC in stage II colon cancer could decrease both the overall and disease-free survival after following up 453 patients for 2 years by e-mails.

Because of these conflicting results, the current consensus guidelines such as the American Society for Clinical Oncology, the European Society for Medical Oncology and the National Comprehensive Cancer Network [12-14] are ambiguous about the chemotherapy for stage II colon cancer (using expressions like "not routinely recommended", "can be considered", etc.), and the chemotherapy is mainly devoted to the clinical judgment of individual medical staff or institution.

The reasons why the study results are confusing may be as follows. First, the characteristics of patients involved in each study could be different because stage II colon cancer has a diverse clinico-pathologic spectrum. Second, the definitions for high- and low-risk groups could be different. Third, the primary outcome of each study could be different. Finally, the treatment outcome of colon cancer can be influenced by other factors such as race, economy scale of the society, medical insurance system, lifestyle, and culture.

Hence, these potential biases must be considered when comparing heterogenous results to that of our study. It must be recognized that big data reflects both the medical and non-medical characteristics of a society. The EURECA study, which analyzed approximately 60,000 patients from seven European countries who had similar racial and social characteristics showed survival differences among the countries after the treatment for stage II colon cancer [8].

The high proportion of patients who received AC is one way in which our study differs from others. The chemotherapy rate was $59.4 \%$ for the high-risk group and $48.2 \%$ for the low-risk group in our study, whereas it was only $21.7 \%$ to $29 \%$ for the high-risk patients in the western countries $[6-8,10]$. This is probably due to the Korean Clinical Practice Guideline for Colon and Rectal Cancer (http://www.colon. or.kr/index.html, only Korean version exists). The Korean guideline recommends observation or use of fluoropyrimidine-based chemotherapy for the low-risk patients, and AC, especially the FOLFOX regimen for the high-risk patients in Korea. Our study could analyze relatively more data on patients receiving chemotherapy because of this differential 
recommendation.

To identify whether our results are consistent with the results of previous studies, it is necessary to compare them with those of racially and socially similar groups. Therefore, it is meaningful that a previous small study with Korean stage II colon cancer patients and the Japanese, which have similar genetic compositions to that of Koreans, presented similar results. Jee et al. [12] performed a study with 363 Korean stage II colon cancer patients and announced that AC was a significantly favorable prognostic factor for survival in both the low- and high-risk groups. Sato et al. [13] reported that $\mathrm{AC}$ was an independent prognostic factor for all patients, and the survival rate of some high-risk group patients was significantly higher.

Our study showed that AC lowered the risk of death by $26 \%$ in the low-risk patients and by $24 \%$ in the high-risk group, even after controlling for the effects of other variables, such as age, gender, BMI, ASA, and other risk factors. If highrisk patients did not receive the chemotherapy, the risk of death increased by more than $170 \%$ in the low-risk patients who did not receive the chemotherapy. On the contrary, the risk of death in high-risk patients was similar to that of lowrisk patients without the chemotherapy when they received the chemotherapy. In patients without the chemotherapy, the HR increased as the involved number of risk factors increased. However, in patients who received chemotherapy, involving one more risk factor did not lead to a significant increase in hazard ratio. This means the more the risk factors involved, the worse the survival rate, and chemotherapy can offset this effect to some degree. This was also seen in the results from previous studies [6,9].

In a subgroup analysis of patients aged 70 years or older, $\mathrm{AC}$ was found to have a positive effect on survival. Because of possible adverse effects on survival due to the side effects of chemotherapeutic agents, chemotherapy is not recommended for elderly patients. However, the use of AC for older patients in stage III colon cancer has been shown to increase survival [14-16]. Although Hernosillo-Rodriguez et al. [17] showed the effect of AC in elderly patients in their study of high risk stage II and stage III colon cancer patients, this study is the first to analyze the effectiveness of AC in elderly stage II colon cancer patients to the author's knowledge. It is important to note that the survival rates of elderly patients with AC were significantly higher in both the lowand high-risk groups.

Another issue in chemotherapy for stage II colon cancer is the addition of oxaliplatin to the regimen. In the 1990s, fluorouracil-based AC for stage III colon cancer was found to have a beneficial effect on survival $[18,19]$, and after about 10 years, the advantage of adding oxaliplatin was well established for stage III colon cancer [20-22]. However, it is vague for stage II colon cancer because data from stage II patients were usually analyzed with those of stage III patients as in NSABP study [22] or Gill et al. [23] There was no difference in OS among the regimens in the MOSAIC study [21]. The ACCENT study [20], which is a pooled analysis of randomized controlled trials, also concluded that the addition of oxaliplatin did not affect the OS. This was also the case in a recent study of 153,000 patients [6]. However, the Korean recommendation for colorectal cancer treatment is primarily to add oxaliplatin to the high-risk patients.

Our study revealed that there was no survival difference between the 592 patients without oxaliplatin and the 567 patients with oxaliplatin in high risk group patients through the multivariate analysis. It is quite a small number to be conclusive. However, adding oxaliplatin to chemotherapy regimen increases the medical cost and the risk of neurotoxicity up to $50 \%$ in patients, which significantly reduces the quality of life [24]. Hence, addition of oxaliplatin to the chemotherapeutic regimen for stage II colon cancer must be cautious until solid evidence is established. In other words, it can be used when there are many risk factors involved, when a patient actively agrees with the oxaliplatin usage after full explanation about the uncertain survival benefit and the possibility of neurotoxicity.

The limitations of this study are as follows. First, selection bias could have occurred from its retrospective design. The fact that the chemotherapy was more prevalent in male patients less than 70 years of age and ASA grade I or II patients may indicate the patients who were healthy enough to receive the chemotherapy and therefore had a higher chance of survival would have received the chemotherapy. However, our results demonstrated that chemotherapy was still a significant factor for OS even after adjustment for the effects of these factors. Second, the big data itself presents a limitation. We could not confirm whether the AC was on a complete schedule. Therefore, it is assumed that chemotherapy was completed when the chemotherapy was just started. Also, cancer recurrence was not checked, and the checked risk factor variables were different for each evaluation period. Therefore, there was many missing data, and of the patients classified as low-risk groups, in fact, there may be patients might have been classified as high-risk group if all needed variables had been checked. The analysis about the effect of number of involved risk factors could also be biased. Because the patients included in the definition of high risk group differed by year, we examined the effect of chemotherapy on high-risk and low-risk patients after adjusting the effect of year variable (S2 Table). Regardless of the year (except only for the low risk group of year 2011), chemotherapy showed a significant benefit in survival. Third, the follow-up period was relatively short. Follow-up periods of more than 5 years would be necessary to fully confirm the impact of therapy on survival. However, we expect that the 
tendency of the survival curve is difficult to change according to the results of ACCENT trial [20], which showed that the risk of death was highest 2 years after the treatment, stable between 2-4 years, and then diminished after 4 years. Median follow-up periods of more than 3 years of our study may be enough, but we are planning the following study with same data for the longer follow-up period. Fourth, other factors that could affect the treatment outcome of stage II colon cancer were not included. Responses to chemotherapy or survival rate may be different according to MSI status, and socioeconomic status of individual may also affect treatment outcome $[25,26]$.

Despite these limitations, this study is meaningful for the first analysis of the status and results of treatment for stage II colon cancer in Korea through nation-wide data. The results showed that the $\mathrm{AC}$ was the independent favorable prognostic factor for survival for the stage II colon cancer patients regardless of age, risk-group status, and chemother- apy regimen.

In conclusion, this study suggests that AC for stage II colon cancer patients would be beneficial. However, addition of oxaliplatin to the chemotherapeutic regimen must be selective until sufficient evidence to prove its survival benefit are accumulated. Additional follow-up data need to be analyzed, and a prospective multicenter trial can be considered based on these data.

\section{Electronic Supplementary Material}

Supplementary materials are available at Cancer Research and Treatment website (http:// www.e-crt.org).

\section{Conflicts of Interest}

Conflict of interest relevant to this article was not reported.

\section{References}

1. Wolmark N, Rockette H, Fisher B, Wickerham DL, Redmond $\mathrm{C}$, Fisher ER, et al. The benefit of leucovorin-modulated fluorouracil as postoperative adjuvant therapy for primary colon cancer: results from National Surgical Adjuvant Breast and Bowel Project protocol C-03. J Clin Oncol. 1993;11:1879-87.

2. Quasar Collaborative Group, Gray R, Barnwell J, McConkey C, Hills RK, Williams NS, et al. Adjuvant chemotherapy versus observation in patients with colorectal cancer: a randomised study. Lancet. 2007;370:2020-9.

3. Wilkinson NW, Yothers G, Lopa S, Costantino JP, Petrelli NJ, Wolmark N. Long-term survival results of surgery alone versus surgery plus 5-fluorouracil and leucovorin for stage II and stage III colon cancer: pooled analysis of NSABP C-01 through $\mathrm{C}-05$. A baseline from which to compare modern adjuvant trials. Ann Surg Oncol. 2010;17:959-66.

4. Efficacy of adjuvant fluorouracil and folinic acid in B2 colon cancer. International Multicentre Pooled Analysis of B2 Colon Cancer Trials (IMPACT B2) Investigators. J Clin Oncol. 1999; 17:1356-63.

5. Buyse M, Piedbois P. Should Dukes' B patients receive adjuvant therapy? A statistical perspective. Semin Oncol. 2001;28 (1 Suppl 1):20-4.

6. Casadaban L, Rauscher G, Aklilu M, Villenes D, Freels S, Maker AV. Adjuvant chemotherapy is associated with improved survival in patients with stage II colon cancer. Cancer. 2016;122:3277-87.

7. Booth CM, Nanji S, Wei X, Peng Y, Biagi JJ, Hanna TP, et al. Adjuvant chemotherapy for stage II colon cancer: practice patterns and effectiveness in the general population. Clin Oncol (R Coll Radiol). 2017;29:e29-38.
8. Breugom AJ, Bastiaannet E, Boelens PG, Iversen LH, Martling A, Johansson R, et al. Adjuvant chemotherapy and relative survival of patients with stage II colon cancer: A EURECCA international comparison between the Netherlands, Denmark, Sweden, England, Ireland, Belgium, and Lithuania. Eur J Cancer. 2016;63:110-7.

9. Verhoeff SR, van Erning FN, Lemmens VE, de Wilt JH, Pruijt JF. Adjuvant chemotherapy is not associated with improved survival for all high-risk factors in stage II colon cancer. Int J Cancer. 2016;139:187-93.

10. Kumar A, Kennecke HF, Renouf DJ, Lim HJ, Gill S, Woods R, et al. Adjuvant chemotherapy use and outcomes of patients with high-risk versus low-risk stage II colon cancer. Cancer. 2015;121:527-34.

11. Lewis C, Xun P, He K. Effects of adjuvant chemotherapy on recurrence, survival, and quality of life in stage II colon cancer patients: a 24-month follow-up. Support Care Cancer. 2016;24:1463-71.

12. Jee SH, Moon SM, Shin US, Yang HM, Hwang DY. Effectiveness of adjuvant chemotherapy with 5-FU/leucovorin and prognosis in stage II colon cancer. J Korean Soc Coloproctol. 2011;27:322-8.

13. Sato H, Maeda K, Sugihara K, Mochizuki H, Kotake K, Teramoto T, et al. High-risk stage II colon cancer after curative resection. J Surg Oncol. 2011;104:45-52.

14. Abraham A, Habermann EB, Rothenberger DA, Kwaan M, Weinberg AD, Parsons HM, et al. Adjuvant chemotherapy for stage III colon cancer in the oldest old: results beyond clinical guidelines. Cancer. 2013;119:395-403.

15. Sanoff HK, Carpenter WR, Sturmer T, Goldberg RM, Martin 
CF, Fine JP, et al. Effect of adjuvant chemotherapy on survival of patients with stage III colon cancer diagnosed after age 75 years. J Clin Oncol. 2012;30:2624-34.

16. Hines RB, Bimali M, Johnson AM, Bayakly AR, Collins TC. Prevalence and survival benefit of adjuvant chemotherapy in stage III colon cancer patients: comparison of overall and agestratified results by multivariable modeling and propensity score methodology in a population-based cohort. Cancer Epidemiol. 2016;44:77-83.

17. Hermosillo-Rodriguez J, Anaya DA, Sada Y, Walder A, Amspoker AB, Berger DH, et al. The effect of age and comorbidity on patient-centered health outcomes in patients receiving adjuvant chemotherapy for colon cancer. J Geriatr Oncol. 2013;4:99-106.

18. Efficacy of adjuvant fluorouracil and folinic acid in colon cancer. International Multicentre Pooled Analysis of Colon Cancer Trials (IMPACT) investigators. Lancet. 1995;345:939-44.

19. O'Connell MJ, Mailliard JA, Kahn MJ, Macdonald JS, Haller DG, Mayer RJ, et al. Controlled trial of fluorouracil and lowdose leucovorin given for 6 months as postoperative adjuvant therapy for colon cancer. J Clin Oncol. 1997;15:246-50.

20. Shah MA, Renfro LA, Allegra CJ, Andre T, de Gramont A, Schmoll HJ, et al. Impact of patient factors on recurrence risk and time dependency of oxaliplatin benefit in patients with colon cancer: analysis from modern-era adjuvant studies in the Adjuvant Colon Cancer End Points (ACCENT) database. J Clin Oncol. 2016;34:843-53.

21. Andre T, Boni C, Navarro M, Tabernero J, Hickish T, Topham $\mathrm{C}$, et al. Improved overall survival with oxaliplatin, fluorouracil, and leucovorin as adjuvant treatment in stage II or III colon cancer in the MOSAIC trial. J Clin Oncol. 2009;27: 3109-16.

22. Kuebler JP, Wieand HS, O'Connell MJ, Smith RE, Colangelo LH, Yothers G, et al. Oxaliplatin combined with weekly bolus fluorouracil and leucovorin as surgical adjuvant chemotherapy for stage II and III colon cancer: results from NSABP C-07. J Clin Oncol. 2007;25:2198-204.

23. Gill S, Loprinzi CL, Sargent DJ, Thome SD, Alberts SR, Haller DG, et al. Pooled analysis of fluorouracil-based adjuvant therapy for stage II and III colon cancer: who benefits and by how much? J Clin Oncol. 2004;22:1797-806.

24. Tofthagen C. Surviving chemotherapy for colon cancer and living with the consequences. J Palliat Med. 2010;13:1389-91.

25. Watson MM, Soreide K. The prognostic yield of biomarkers harvested in chemotherapy-naive stage II colon cancer: can we separate the wheat from the chaff? Mol Med. 2016;22:271-3.

26. Smith JJ, Tilney HS, Heriot AG, Darzi AW, Forbes H, Thompson MR, et al. Social deprivation and outcomes in colorectal cancer. Br J Surg. 2006;93:1123-31. 